\title{
DEPREDACIÓN DE ANOLIS PORCATUS (SQUAMATA: DACTYLOIDAE) POR PASSER DOMESTICUS (AVES: PASSERIFORMES) EN CUBA
}

\author{
Jorge Luis Guerra Solana ${ }^{1}$ y Luis F. de Armas ${ }^{2}$ \\ Instituto de Ecología y Sistemática, carretera de Varona No. 11835, entre Oriente y Lindero, \\ Reparto Parajón, Municipio Boyeros, La Habana 19, C.P. 11900, Cuba. \\ ecosr08@gmail.com1, luisdearmas1945@gmail.com²
}

\section{RESUMEN}

Se registra el segundo caso en Cuba de depredación de lagartos anolinos por el Gorrión Común, Passer domesticus (Linnaeus, 1758) y se documenta fotográficamente.

Palabras clave: Gorrión Común, lagartija, alimentación, Antillas.

\section{PREDATION OF ANOLIS PORCATUS (SQUAMATA: DACTYLOIDAE) \\ BY PASSER DOMESTICUS (AVES: PASSERIFORMES) IN CUBA}

\begin{abstract}
The second case of predation of Cuban anole lizards by the House Sparrow, Passer domesticus (Linnaeus, 1758), is herein recorded and supported by photos.
\end{abstract}

Keywords: House Sparrow, lizard, feeding, West Indies.

El Gorrión, Passer domesticus (Linneo, 1758), es una especie ampliamente distribuida y asociada a los asentamientos humanos. Proveniente del Viejo Mundo, fue introducida en Cuba por los españoles a mediados del siglo XIX (Garrido y García, 1975). Extensivamente estudiada, su biología es bien conocida, aunque mayormente en cuanto a los aspectos reproductivos (Barnard, 1980; Anderson, 2006; Lowther y Cink, 2006; Morrison et al., 2008; Bókony et al., 2009; López de Hierro y de Neve, 2010).

De hábitos alimentarios omnívoros, esta especie consume principalmente semillas y hace uso ocasional de presas animales, como insectos y otros artrópodos, para suplir los requerimientos nutricionales durante la reproducción (Alonso, 1985; Lowther y Cink, 1992; Murgui, 2011). Dentro de su dieta también ha sido reportado, en ambientes urbanos, el uso oportunista de néctar de flores (Leveau, 2008) y de algunos vertebrados (Anderson, 2006).

Acosta y Mugica (1989) abordaron aspectos de la variabilidad morfométrica de $P$. domesticus en las poblaciones cubanas; pero respecto a su dieta en el país, la información disponible es muy escasa y general (Garrido y García, 1975). Bello (2000), observó en La Habana gorriones que atacaron a dos especies de pequeños lagartos que identificó, uno como Gonatodes albogularis Duméril y Bibron, 1836 (Sphaerodactylidae) y otro como Anolis sp., probablemente A. porcatus Gray, 1841, este último un individuo muy joven, cerca del cual había adultos $A$. porcatus. Pérez y Ayón (2002) mencionaron que los gorriones exhiben con frecuencia la conducta de persecución de lagartijas del género Anolis, principalmente de A. sagrei y A. porcatus, pero no refirieron ningún caso concreto de depredación.

El objetivo de la presente contribución es dar a conocer un nuevo caso de depredación de lagartijas anolinas por $P$. domesticus en una localidad urbana del occidente de Cuba. 
El 30 de abril de 2013, en el patio de una vivienda en San Antonio de los Baños $\left(22.89^{\circ} \mathrm{N}-82.50^{\circ} \mathrm{O} ; 70 \mathrm{~m} \mathrm{snm}\right)$, provincia de Artemisa, a las 15:00 h, se observó un gorrión que atacaba a un adulto de Anolis porcatus por la cabeza y lo capturaba, matándolo al instante para comérselo (fig. 1); pero ante un disturbio propio del ambiente urbano, abandonó al lagarto en el suelo. Este fue recogido y conservado en etanol al 75\%. La presa tenía la cabeza totalmente destruida y le faltaba parte de la cola. La muestra fue depositada en la colección herpetológica del Instituto de Ecología y Sistemática (IES), La Habana.

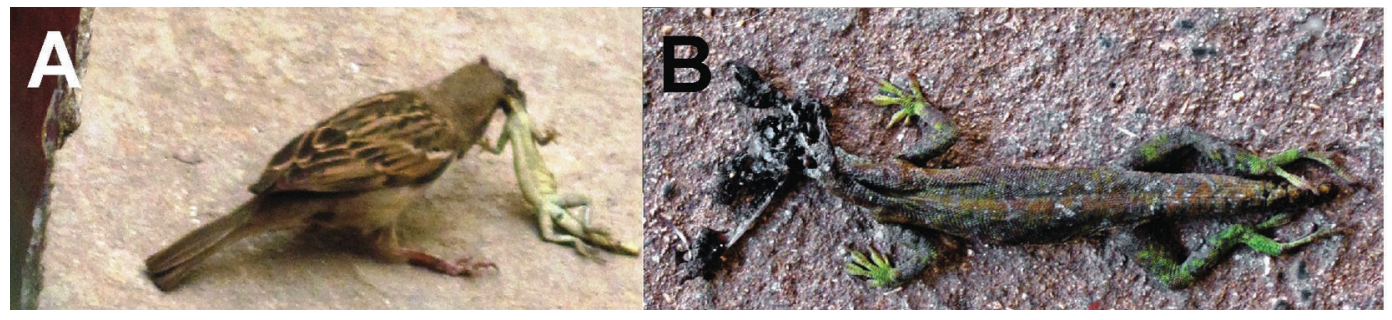

FIGURA 1. A, Gorrión (Passer domesticus) en el acto de depredar a una lagartija adulta (Anolis porcatus). $\mathrm{B}$, vista dorsal de la lagartija depredada (ejemplar testigo en la colección herpetológica del IES).

Al parecer, esta conducta depredadora constituye una práctica frecuente, ya que en varios días, en esta misma localidad, fue observada la persecución de que son objetos las lagartijas, por lo general por un solo gorrión, pero a veces por dos en colaboración, lo que soporta la idea, sugerida por Bello (2000), de que la depredación de Anolis spp. por el Gorrión Común, pudiera ser un factor importante en la dinámica poblacional de estos reptiles.

Con el presente registro, se confirma categóricamente la depredación de A. porcatus por el Gorrión Común.

\section{LITERATURA CITADA}

Acosta, M. y L. Mugica. 1989. Caracterización morfoecológica de una colonia de gorriones (Passer domesticus) en estadio preadulto. Reporte de Investigación del Instituto de Ecología y Sistemática, 7:1-8.

Alonso, J. C. 1985. La alimentación del Gorrión Común (Passer domesticus) en áreas de cultivo de regadío. Ardeola, 32 (2): 405-408.

Anderson, T. R. 2006. Biology of the ubiquitous House Sparrow: From genes to populations. Oxford University Press, $560 \mathrm{pp}$.

Barnard, C. J. 1980. Flock feeding and time budgets in the House Sparrow (Passer domesticus L.). Animal Behavior, 28: 295-309.

Bello, R. E. 2000. Anolis sp. and Gonatodes albogularis (Yellowheaded Gecko) predation. Herpetological Review, 31(4): 239.

Bókony, V., A. Kulcsár y A. Liker. 2009. Does urbanization select for weak competitors in House sparrows? Oikos, 119: 437-444.

Garrido, O. H. y F. García. 1975. Catálogo de las aves de Cuba. Academia de Ciencias de Cuba, La Habana, 149 pp. 
Leveau, L. M. 2008. Dynamics of nectarivory in the House Sparrow in an urban environment. Ornitología Neotropical, 19: 275-281.

López de Hierro, M. D. y L. de Neve. 2010. Pigment limitation and female reproductive characteristics influence egg shell spottiness and ground colour variation in the House Sparrow (Passer domesticus) Journal of Ornithology, 151: 833-840.

Lowther, P. E. y C. L. Cink. 1992. House Sparrow (Passer domesticus). En The Birds of North America Online (A. Poole, P. Stettenheim y F. Gill, Eds.). Philadelphia Academy of Sciences, Philadelphia. Disponible en http://bna.birds.cornell.edu/bna/species/012. doi:10.2173/bna.12. Consultado el 4 de febrero de 2017.

Morrison, E. B., T. B. Kinnard, I. R. K. Stewart, J. P. Poston, M. I. Hatch y D. F. Westneat. 2008. The links between plumage variation and nest site occupancy in male house sparrows. The Condor, 110: 345-353.

Murgui, E. 2011. Gorrión común - Passer domesticus (Linnaeus, 1758). Enciclopedia Virtual de los Vertebrados Españoles (A. Salvador y M. B. Morales, Eds.). Museo Nacional de Ciencias Naturales, Madrid. Disponible en http://www.vertebradosibericos.org/.

Pérez, E. y X. Ayón. 2002. Las aves de la ciudad. Pp. 136-141 en Aves de Cuba (H. González, ed.), UPC Print, Vaasa, Finlandia, 161 pp. 